\title{
Evolution on a Restless Planet: Were Environmental Variability and Environmental Change Major Drivers of Human Evolution?
}

\author{
Peter J. Richerson, Robert L. Bettinger, and Robert Boyd
}

7.1

Introduction

Two kinds of factors set the tempo and direction of organic and cultural evolution, those external to biotic evolutionary process, such as changes in the earth's physical and chemical environments, and those internal to it, such as the time required for chance factors to lead lineages across adaptive valleys to a new niche space (Valentine 1985). The relative importance of these two sorts of processes is widely debated. Valentine (1973) argued that marine invertebrate diversity patterns responded to seafloor spreading as this process generated more or less niche space. He suggested that natural selection is a powerful force and that earth's biota are in near equilibrium with the niches available on the geological time scale. Walker and Valentine (1984) modeled the evolution of species assuming a logistic speciation rate limited by internal factors and a diversity-independent death rate caused by ongoing environmental change. Fitting this model to the observed evolution of shelled marine invertebrates suggests that the lag between extinctions and the evolution of new species leaves perhaps $30 \%$ of ecological niches unfilled. In this model, the biota lag environmental change by perhaps a few million years.

However, as Valentine (1985) notes, if adaptive landscapes have whole suites of niches protected by deep maladaptive valleys, the waiting time for some pioneering species to cross the divide may be very long, generating the rare events that set new body plans and generate major adaptive radiations. Eldredge and Gould (1972) and Gould (2002) championed the idea that internal processes such as genetic and developmental constraints, coupled with the complexity of the adaptive landscape, resulted in a highly historically contingent evolutionary process. On Gould's account, most of the history of life had to do not with a relatively close tracking of a changing environment but with the halting evolutionary exploration a deeply fissured niche space, mostly by rapid bursts of evolution as a fissure was crossed, followed by long periods of stasis. Note that if the adaptive landscape is deeply fissured for any reason, evolution may take on a progressive character (Stewart 1997). Imagine that the original simple forms of life began at the foot of a large mountain range of

Handbook of Evolution, Vol. 2: The Evolution of Living Systems (Including Hominids)

Edited by Franz M. Wuketits and Francisco J. Ayala

Copyright (C) 2005 Wiley-VCH Verlag GmbH \& Co. KGaA, Weinheim

ISBN: 3-527-30838-5 
adaptive topography. Potentially, the whole history of life has been a halting and episodic process of moving first onto to local optima of the near foothills and subsequently filtering across adaptive chasms to higher peaks deeper into the complex topography. Perhaps we have not yet come anywhere near to reaching the highest peaks in the topography on earth, even after perhaps 3.5 billion years of life on our planet.

More complex scenarios are possible. Vermeij (1987) argues that much evolution is driven by the top-down biotic process of predator-prey coevolution, but that the degree of escalation of predator attack strategies and prey defenses is limited by external factors, especially those that control productivity. Vermeij does not commit himself on the issue of how closely the predator-prey escalation process tracks external environmental change.

Discussions of the large-scale patterns of evolution typically assume that the overall environmental framework of the earth is static and that changes in features like the size of brains represent a series of progressive changes from simpler to more complex organisms. Billions of years have transpired since the origins of life on earth, and about 540 million years have transpired between the abundant fossil animals of the Cambrian and the evolution of humans. If the earth's environment has been essentially constant since either the origin of life or even the beginning of the Cambrian, the growth of organic complexity by natural selection and other evolutionary processes such as species selections would have to have been so limited by internal processes as to be exceedingly slow.

On the other hand, since the discovery of seafloor spreading 40 years ago, the role of external factors in macroevolutionary processes has become much clearer (Valentine 1973). Today we have a reasonably clear picture of past continental configurations and past biogeochemistry, especially the chemistry of the oceans and atmosphere (Holland 1984; Scotese 2003). Past environments were very different from those of today. For example, during the late Paleozoic, high oxygen concentrations in the atmosphere supported gigantic flying forms, including dragonflies a meter long and pterosaurs weighing perhaps $100 \mathrm{~kg}$. (Graham et al. 1995; Dudley 2000). Everyone accepts, we suppose, that external processes are important regulators of the rate and direction of evolution in the very long run, and everyone accepts that evolution is not an instantaneous process. At the most extreme, life on earth could not begin to evolve until the earth formed, and new species do not evolve in one generation. But the gap is very wide between those that argue that most of the history of life, at least since the late Precambrian, is mainly regulated by internal processes and those that think that, for the most part, the earth's biota are in near equilibrium with existing environmental conditions, aside from a few empty niches resulting from relatively short-term constraints operating on evolutionary processes.

Discussions of human evolution are especially prone to adopt a progressive explanation (e.g., Bronowski 1973; Lenski and Lenski 1982). The implicit hypothesis seems to be that humans are adaptively superior to all other animals, so superior as to constitute a new grade of the evolution of life, equivalent in magnitude to the evolution of multicellular animals (Maynard Smith and Szathmary 1995). If humans 
or similar creatures had evolved in the Cretaceous, say, the subsequent biotic history of the earth would have been transformed.

Recent discoveries in paleobiogeochemistry and paleoclimatology suggest that we should take a hard look at the internal and progressive account of human origins. Cenozoic, especially Plio-Pleistocene, climate changes probably exerted selective pressures favoring large brains and systems of cultural evolution. The climate deterioration of the last few million years resulted in high-amplitude variation in climates on the scale of the classic glacial advances and retreats (21 000-100 000) years. These variations are too slow to favor adaptation by behavioral flexibility and culture. During the last few glacial cycles, however, the ice ages were accompanied by high-amplitude fluctuations on time scales of a millennium or less. Theory suggests that these are the time scales that can favor the evolution of costly systems for adapting to variable environments by individual learning and cultural transmission. On millennial and submillennial time scales, range changes and organic evolution are too slow to approximate adaptive equilibrium in many habitats. Evolution thus favors big-brained creatures that can adapt rapidly by behavioral means. Human culture is particularly suited to highfrequency fluctuating environments, because humans can use cumulative cultural evolution to develop quite fancy adaptations to particular environments on time scales of a few decades to a few millennia. Even so, the 11 000-year-long Holocene period of climate stability, which led to the origins of plant cultivation and eventually to the exceedingly complex societies and technology of the present, shows that the rate of cultural evolution lags behind environmental change by ten or more millennia.

\section{2}

\section{The Evolution of Cenozoic Environments}

The last 65 million years of earth history have been quite dynamic. Zachos et al. (2001) and Barrett (2003) provide recent summaries. The Cenozoic began with the southern continents still close to Antarctica. Warm currents penetrated to high latitudes in the Southern Hemisphere, maintaining a temperate, if highly seasonal, environment in Antarctica. The Northern Hemisphere was also ice-free. As India, South America, and Australia drifted northward, a seaway circling the Antarctic continent opened and the circum-Antarctic current systems developed. These current systems insulated Antarctica from warming currents, and ice sheets began to develop on that continent as early as about 38 million years ago. The collision between India and Asia began to raise the Tibetan Plateau around 35 million years ago. Ice and high-elevation dry plateaus are very bright, reflecting sunlight back to space. Thus, the net heat income of the whole earth declined, cooling the entire globe. A number of other still poorly understood processes modulated the effects of continental drift and ocean circulation reorganization. The earth warmed abruptly at the end of the Oligocene about 26 million years ago, and cooling did not resume until the mid-Miocene about 15 million years ago. 
From the mid-Miocene onwards, mean temperatures have dropped and oscillations of climate have increased in several steps. Opdyke (1995) provides a summary the data (Figure 7.1). During the latter half of the Miocene, the climate variation was dominated by a 23 000-year quasi-cycle driven by the wobble of the earth's axis of rotation (causing precession of the equinoxes). By changing the seasonal heat income of different regions of the earth, changes in this and other orbital parameters influence the earth's climate. For example, when high-latitude summers are cool in the Northern Hemisphere, large glaciers form on high-latitude land masses. The direct effects of the orbital parameters are rather modest, and they must have their main effects via complex, poorly understood climate feedbacks (Broecker 1995; Bradley 1999). Continental drift and other geological factors have recently changed the way the earth's climates respond to orbital fluctuations. In the late Pliocene, a little more than three million years ago, a two million year period of steady cooling of the earth's climate began. At the same time, the variation in climate increased sharply and came to be dominated by the 41000 -year quasi-cycle caused by variation in the tilt of the earth's axis of rotation. Then, after about one million years ago in the middle of the Pleistocene, the overall cooling trend stopped, but the climate variation increased dramatically, now in tune especially with the 100000 -year quasicycle of the eccentricity of the earth's orbit (the degree to which the earth's orbit around the sun is elliptical rather than circular). The low-resolution record from Antarctica and the Southern Ocean shows a further distinct change about 420000

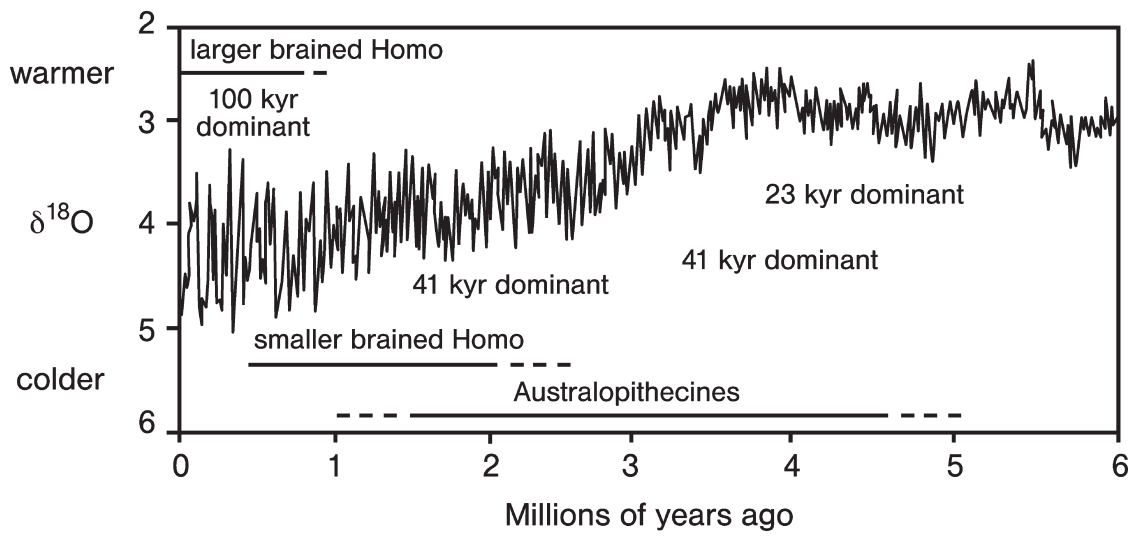

Figure 7.1 A composite marine core record of climate deterioration since the mid-Miocene. During cold periods the oceans are enriched in the heavy ${ }^{18} \mathrm{O}$ isotope, which serves as a proxy for paleotemperature. Periods during which different orbital quasi-cycles dominate the variation in paleotemperatures are indicated. The time lines for important groups of hominin taxa are indicated. Australopithecines include both gracile and robust forms from Australopithecus ramidus to A. robustus. The line for small-brained Homo includes $H$. rudolfensis, $H$. erectus, and $H$. ergaster. The line for large-brained Homo includes $H$. heidelbergensis, $H$. neanderthalensis, and H. sapiens. Redrawn from Opdyke (1995), Hominin time lines adapted from Klein (1999). 
years ago (Becquey and Gersonde 2002; EPICA 2004). The causes of these changes are at present poorly understood, but the upshot is the periodic advance and retreat of high-latitude and mountain glaciers on a massive scale, cycles of aridity in the tropics, changes in ocean current systems, and a host of related environmental changes. For example, drops in mean global temperature affect the earth's water budget. Cold periods mean less water vapor generated by evaporation from tropical oceans and less rainfall over the continents. Deserts and grasslands have expanded greatly at the expense of forests in the last few million years, and wetter and drier habitat types expand and contract dramatically over glacial-interglacial cycles. Whole suites of new mammalian species evolved to live in these drier environments, including our early bipedal ancestors (deMenocal 1995; Potts 1996; deMenocal 2004).

\section{3}

\section{Climate and the Evolution of Large Brains and Cultural Artifacts}

The most important factor in the evolution of hominins and other large-brained creatures was likely the development of variation at quite short time scales. Animal learning and, as we shall see, human culture are adaptations to environmental changes on time scales of less than one to perhaps a few hundred generations. Animals adapt to changes on the order of thousands of generations by range changes and organic evolution rather than by mechanisms of phenotypic flexibility. The variation driven by the relatively long time scales of the orbitally tuned glacial quasicycles has undoubtedly been important in the evolution of many species (Vrba et al. 1995), but the advanced cognitive skills of humans and the rich culture that it supports must be driven by the need to adapt to much more rapid variation. That is, sophisticated nervous systems are mechanisms for adaptive phenotypic flexibility. Large brains are very costly organs and must pay their keep (Aiello and Wheeler 1995). Ordinary learning is an individual-level adaptation and hence is especially suited to environments that vary from generation to generation or to changes that occur within a generation. Human social learning (culture) is a complex and sophisticated system. It is suited to rapid adaptation time scales ranging from less than a generation to tens or even hundreds of generations, depending upon how the cultural system is structured. High-resolution ice cores raised from the Greenland ice cap in the early 1990 s were the first to document a stunning amount of variation on millennial and submillennial scales as illustrated in Figure 7.2 (Johnsen et al. 1992; Alley 2000). Such high-frequency, high-amplitude variation has characterized the last five glacials, whereas the much briefer interglacials have been much less variable, roughly like the current interglacial (McManus et al. 1999). Our knowledge of the onset of high-frequency high-amplitude part of the climate record awaits the collection of longer high-resolution cores from environments like anoxic ocean basins and deep, old lake sediments. No doubt such cores will be produced in the next few years.

We gain some insight into the evolution of high-frequency climate variation by using mammalian brain size evolution as an index of climate variation on the time 
warmer

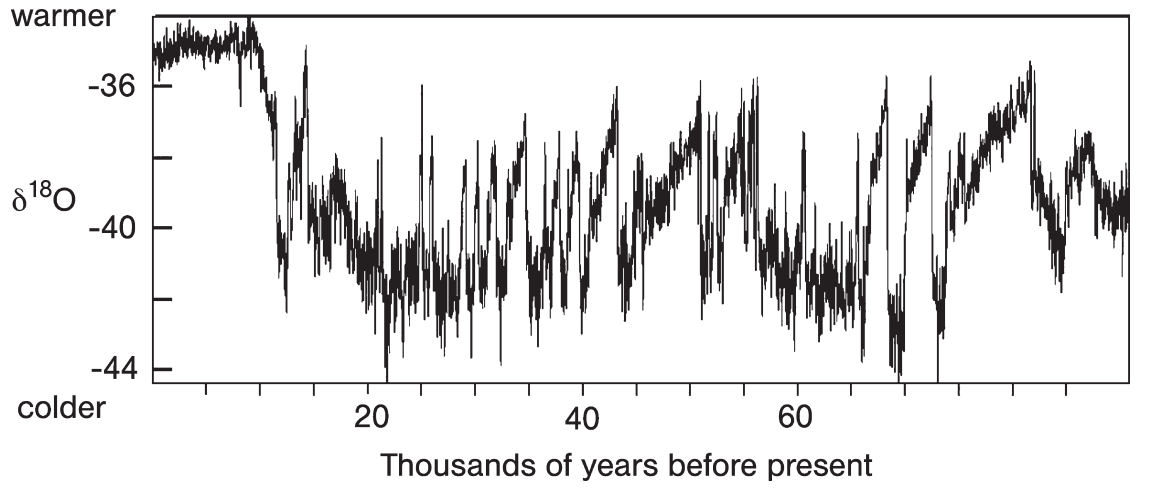

Figure 7.2 The Greenland ice paleotemperature proxy record. During periods of high ice volume ${ }^{18} \mathrm{O}$ is depleted in ice as it accumulates in the ocean. These data are filtered (averaged) using a 150-year low-pass filter, so that variations on the time scale of $\leq 150$ years are not portrayed. The Holocene is the little-varying last 11000 years. Redrawn from Ditlevsen et al. (1996).

scales relevant to phenotypic flexibility. Jerison's (1973) classic study of fossil endocasts of mammal brains indicated a gradual increase in average mammalian brain size throughout the Cenozoic, ending with a sharp increase from the Miocene to the Recent period. The time resolution of this record is very coarse, but it roughly follows the decline in global temperatures and the increase in orbital-scale variation in climate. Ditlevsen et al. (1996) argue that orbital-scale variation should generate a 'variance cascade'. By this argument, increases in variance at low frequencies cause increases in variation at higher frequencies, potentially at scales right down to dayto-day variations in weather. To the resolution of the brain size data, Ditlevsen et al.'s hypothesis seems borne out. Brain sizes increases in mammals roughly parallel the decline in mean global temperature, with much of the increase concentrated in the Pleistocene as high-frequency variation in climate increased dramatically.

The evolution of our lineage over the last few million years has been the subject of intensive study. DeMenocal $(1995,2004)$ summarized the evidence for the relationship between the evolution of climate and human ancestors. Early hominins, up to and including the apparently many species of Australopithecus, resemble modern humans in acquiring bipedal posture but were not encephalized above the range of current nonhuman apes. Australopithecines lived in increasingly arid environments with considerable fluctuation induced by the 21000 -year precessional quasi-cycle. The dominance of the 41000 -year tilt quasi-cycle began about 2.8 million years ago, not long before the first Oldowan stone tool tradition appears at around 2.6 million years ago. The earliest fossils attributed to our genus Homo appeared 2.5-2.3 million years ago. The Acheulean stone tool tradition, significantly more sophisticated than the Oldowan, appeared about 1.6-1.7 million years ago, not long after an intensification of the variation of climate in tune with the tilt cycle. Homo erectus and related species were once thought to have had larger brains than australopithecines, but recent evidence that their bodies were large suggests that 
their degree of encephalization was only modestly advanced over that of the australopithecines and earlier hominins, which in turn were not particularly largebrained compared to living apes. Homo erectus-grade humans were the first hominins to spread out of Africa, reaching the Caucasus by about 1.75 million years ago (Vekua et al. 2002). This is significant if we suppose that adaptations to temporally varying environments also lead to a propensity to adapt to a wide range of contemporaneous environments. The australopiths were certainly diverse in form, but the version of Homo that spread to Eurasia was very similar to the contemporaneous African form, often referred to as the species Homo ergaster, considered by some to be a variant of Homo erectus. The developmental rate of fossil hominins can be estimated from growth lines in their teeth. A slow developmental rate would allow more scope for learning and culture acquisition. Homo erectus/ergaster had a developmental rate only slightly slower than that of living apes and earlier fossil hominins. Later fossils, including $H$. heidelbergensis and neanderthalensis, show development rates intermediate between those of H. erectus and modern humans (Dean et al. 2001; Ramirez Rozzi and Bermudez de Castro 2004).

The onset of the dominance of the 100000 -year eccentricity quasi-cycle was followed by the evolution of distinctly large-brained hominins, usually referred to as the species Homo heidelbergensis or rhodesiensis, whose earliest fossils date to around 500000 years ago in Africa. These populations made tools of a distinctly modern cast compared to the Acheulean industry, although only after about 350000 years ago following the intensification of the 100000 quasi-cycle. McBrearty and Brooks (2000) review the classification of the fossils. Human skeletons sufficiently modern to be classified as $H$. sapiens, but of a distinctly archaic subspecies, date back to at least 154000 years ago in Africa (White et al. 2003). McBrearty and Brooks (2000) outline the progressive modernization of the human toolkit between about 250000 and 50000 years ago in Africa (Figure 7.3). By about 50000 years ago, African tool assemblages contained all the features that characterize modern hunter-gather assemblages. Some elements of this complex occurred quite early in the sequence, including blade-making technology and artifacts derived from blades such as spearpoints, as well as grindstones and associated pigment processing. Bone tools appeared in the middle of the sequence, and symbolic artifacts like beads and artwork were late. About the time the artifact assemblage became fully modern, modern humans spread out of Africa into Eurasia, replacing earlier populations there (Klein 1999).

If the emerging picture of the parallels between ongoing climate deterioration and the evolution of cognitive and cultural complexity is not misleading, it suggests that hominin evolution could well have been driven by climate and that the lag between the onset of a new climate regime and a biotic response in these lineages was quite short, on the order of $\leq 100000$ years. Given that mammals in general evolve rapidly and that in favorable situations many new species of vertebrates can evolve in 100000 years (Verheyen et al. 2003), the idea that hominin evolution has closely tracked increases in high-frequency climate variation is plausible. The climate data are rapidly improving, as are those regarding fossil hominins and their artifacts. 


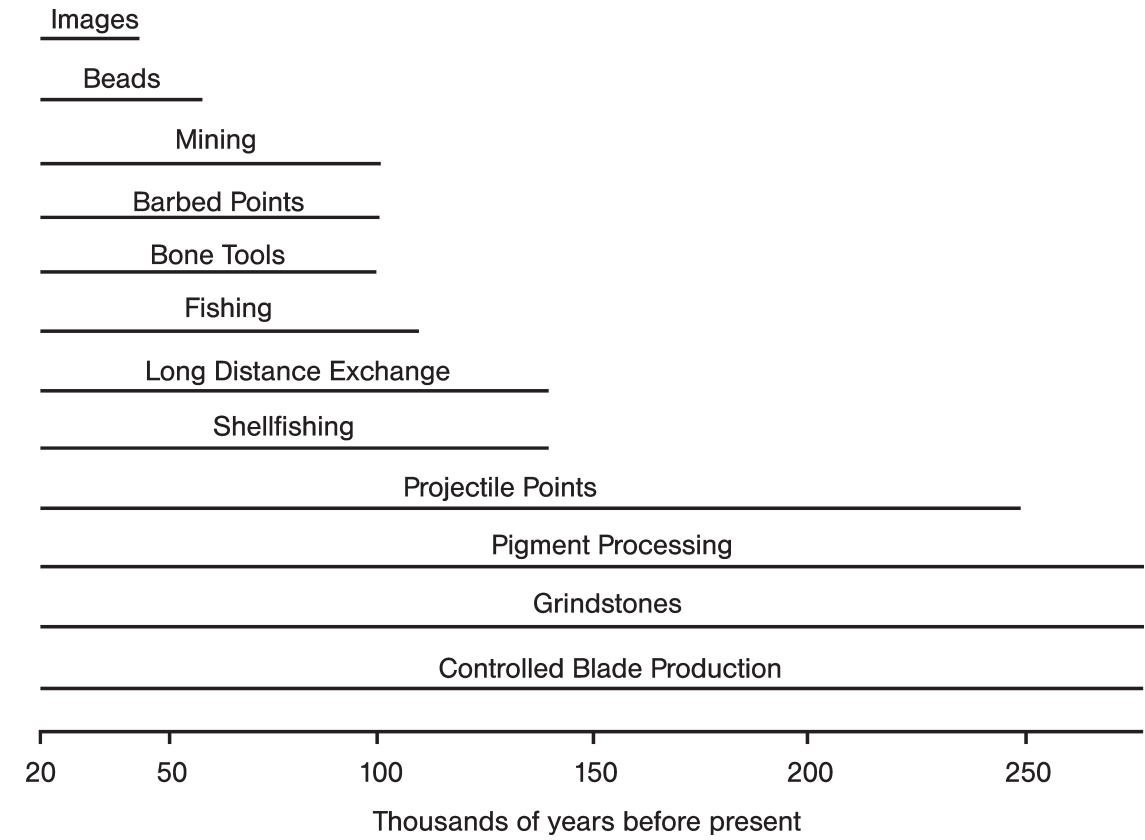

Figure 7.3 Time lines for the acquisition of key components of the artifact assemblage that came to characterize anatomically modern humans in Africa. The spread of modern humans out of Africa took place just after the final modernization. After McBrearty and Brooks (2000).

External hypotheses will become progressively more testable in the near future. The idea that more ancient increases in brain size reflect so-far-undetected increases in high-frequency climate variation reaching back to the beginning of the Cenozoic is obviously more speculative. However, if brain size and associated behavioral sophistication did respond fairly quickly to rapid increases in climate variation in the Plio-Pleistocene, the much slower changes over the preceding 63 million years certainly could be a proxy for climate change.

\section{4}

Learning and Social Learning as Responses to Variability Selection

Potts (1996a,b; 1998a,b) has made a general case that climate variation on various scales has been one of the most important selective agents on hominins over the last few million years. We think that theoretical models of individual and social learning show in detail how variability selection has favored the evolution of a culture-bearing species (Richerson and Boyd 2004, Chapter 4; see also Calvin 2002). Individual learning and the many other forms of individual-level phenotypic flexibility are the main means that most species use to adapt to the highest-frequency 
components of variable environments. Very slow environmental variation favors range changes and organic evolution. Theoretical models suggest that social learning is an effective method of coping with environmental variation with a significant generation-to-generation autocorrelation (Boyd and Richerson 1985, Chapter 4). Even on the within-generation time scale, horizontal transmission of socially learned variants can be highly adaptive. Humans are well known to bias their acquisition of variants using a number of decision-making strategies that enhance the effectiveness of social learning. For example, a conformist bias of the form "adopt the commonest behavior in your set of cultural models" is adaptive under a wide variety of conditions (Henrich and Boyd 1998). A basic feature of many models is that a cultural system of inheritance tracks variable environments more rapidly that genes, because decision-making forces supplement natural selection. Individuals' own learning and biased selection of cultural variants, summed over many individuals, has the population-level consequence of increasing the frequency of adaptive cultural variants even if these decision-making effects are weak. In very slowly changing environments, any extra costs related to having a social learning system, for example the requirement for a large brain, prevent one from arising, since genes track slow change well enough. In very rapidly changing environments, each individual's environment becomes random with respect to every other's, and attempting to use the behavior of others as a clue to one's own adaptive behavior is useless. Over a broad range of intermediate environmental change between these extremes, social learning is favored.

The models suggest that social learning should be common in animals and that it should have become more common as climates deteriorated. Jerison's (1973) data on brain size evolution suggest that many mammalian lineages evolved larger brains in response to Plio-Pleistocene climate deterioration. Reader and Laland (2002) surveyed primates and correlated field estimates of brain size, innovation, social learning, and tool use. All correlations were strongly positive. Other data suggest that individual and social learning should be correlated, because almost all the known nonhuman systems of social learning depend mostly on individual learning. Nonhumans do not have the capacity imitate. Rather, individuals are attracted to the locations or cues that other individuals use to find food, avoid predators, and the like. Then they learn themselves exactly what is good to eat or what should be avoided, mainly by the same individual learning strategies they would use in the absence of social cues. The effect is exemplified by the well studied example of Norway rat social learning (Galef 1996). Rat colonies act like information exchange centers, but all that is exchanged is the smell of foods that a rat has consumed. Rats are prone to sample foods that smell the same as those they have smelled on others in the nest. If the food item is reinforcing, they add the new item to their diet. If not, they do not.

Human social learning differs from that of other animals because we are fast, accurate imitators. Tomasello (1996) and Whiten (2000) evaluated the abilities of chimpanzees and children to imitate using the same tasks demonstrated by human models. Although chimpanzees show some ability to imitate, children as young as two years old do better. Humans are also much more prone to teach each other 
than are apes. The human ability to acquire complex cultural elements by imitation means that populations of humans can evolve complex adaptive traditions relatively quickly. Innovations made by one person can be added to those of others, so the cultural complexity builds up over time. Other animals, dependent mainly on individual learning, cannot acquire traditions more complex than each individual is capable of mastering on its own. Humans evolve traditional artifacts, skills, and social systems of far greater complexity than any one individual can learn unaided. Kayaks, the calculus, and constitutional government are examples. The runaway success of the human species is due to our ability to evolve a diverse array of technologies and social organizations suited to particular environments. Even without agriculture, humans spread to most of the earth's terrestrial surface, including environments far different from our tropical homeland.

\section{5}

\section{Internal Constraints on the Evolution of Human Culture}

Even if all we have argued about the relationship between climate and the evolution of brain size in mammals generally, and hominins in particular, is true, we have to account for why humans but not other species became highly cultural. Given that humans are a spectacular evolutionary success across such a wide range of environments, why have many other species not converged upon the same adaptation? We can think of four internal constraint hypotheses that might explain why humans are such an exceptional species.

7.5.1

Time

Modern humans evolved only in the last few hundred thousand years, and the last elements of our behavioral repertoire perhaps evolved as recently as 50 000-70 000 years ago. Lags on the order of tens to hundreds of thousands of years are reasonable for the evolution of complex adaptations. Perhaps many species will converge on the complex culture adaptation in the future. Arguably, some other lineages such as whales are some way down this path (Moore 1996; Rendell and Whitehead 2001).

7.5.2

\section{Preadaptations}

The hominin lineage had at least two long-standing features that seem to have predisposed humans to adopting culture. The upright posture left the hands free to respond to selection for tool-making. The relatively large brain of our ancestral apes likely gave them an initial advantage in the evolution of a brain large enough to manage imitation and complex cultural traditions. Most students of hominin evolution accept that large brains and free hands played a role in the evolution of humans. Other features have been nominated. For example, Maryanski and Turner 
(1992) argue that apes have relatively flexible social systems that could easily respond to selection to become entrained by culturally evolved norms to create highly variable social systems. Social organization does stand beside technology as a major pillar of our system of adaptation by cultural traditions.

\subsection{3}

\section{Functional Constraints}

The capacity to learn complex cultural traditions by imitation and teaching may have difficulty increasing when rare (Boyd and Richerson 1996). Suppose that imitation and teaching require a costly investment in brain tissue. When such capacities are rare, populations are unable to sustain complex traditions. Thus, when the capacity is rare, its adaptive advantage - the rapid, low-cost acquisition of complex, locally adapted technology and social organization - is absent. The first culture-capable individual would find no culture to imitate. Even worse, the evidence suggests that human societies have to be rather large to sustain the complex traditions of typical hunter-gatherers (Henrich forthcoming). On Tasmania, technology became dramatically simplified compared to that in Australia after the flooding of the Bass Strait made it an island and reduced its population to a few thousand. Perhaps humans evolved the intelligence necessary to acquire culture initially as the byproduct of another adaptation that lacked the problem of increasing when rare. That human intelligence originally evolved to play sophisticated social games rather than for imitation is one such suggestion (Dunbar 1998).

\section{5 .4}

\section{Cultural Diversification}

Major evolutionary innovations typically lead to flocks of species exploiting the innovation, often including convergent adaptations from diverse lineages (Price 2003). Humans are an exception in that a single species has achieved unprecedented dominance of the globe. However, in an ecological and cultural sense, humans do constitute a highly diversified adaptive radiation. Men and women tend to divide labor based on different skills traditionally assigned to one or the other. In simple societies, social and technological traditions vary enormously by place and time. In modern societies, the skills needed to practice different professions differ so extremely that few people can master more than one. Once our species became good at rapid cultural adaptation, we probably tended to fill many of the niches where adaptation by tradition was favored, confronting other species with effective competition for the 'cognitive niche' (Tooby and DeVore 1987). Until the late Pleistocene, hominins were a diverse lineage with typically several species extant at any one time. The probable extirpation of Neanderthals and other archaic hominin species by modern humans reduced us to one biological species not long after we became fully modern in the biological sense. Modern humans, however, show much more variation in both stylistic and functional features of their artifacts than earlier hominins. Interestingly, many of the most sophisticated nonhuman social learners 
are not primates, but birds (Moore 1996) and whales (Rendell and Whitehead 2001), groups of animals with relatively little niche overlap with humans.

Constraints and opportunities such as these are probably sufficient to explain why the hominin lineage rather than some other led to the evolution of modern humans. The future of human evolution is much harder to know. Are we a breakthrough species that amounts to the evolution of a new grade of organism (Maynard Smith and Szathmary 1995)? Or are we an ice-house flower with a costly investment in a cultural system of inheritance that may have no utility in the environments of the future?

\section{6}

\section{Cultural Evolution in the Late Pleistocene and Holocene}

Cultural evolution over the past 50000 or so years exhibits a roughly progressive dynamic. At the beginning of this period, all humans lived in small-scale hunting and gathering societies. Today, human populations are vastly larger. Both technology and social organization are much more sophisticated. This pattern seems to encourage progressive interpretations without leading to explicit hypotheses about mechanisms that would sustain progress. The details of cultural evolutionary trajectories in contrast lead to several explicit hypotheses invoking external controls of cultural evolution.

\subsection{1}

\section{Holocene Climates and the Origins of Agriculture}

The late Pleistocene cultures of modern humans progressed only slightly, to judge by the excellent archaeological record from Europe. Almost all the progress relative to our ancestral hunting and gathering adaptation is due to the subsistence revolution made possible by plant and animal domestication beginning about 11000 years ago. Agriculture is a Holocene phenomenon. Holocene climates have been much more stable than those of the last glacial. They also have been wetter on average and have higher carbon dioxide concentrations. We have argued that lastglacial climates probably made agriculture impossible (Richerson et al. 2001). In contrast, Holocene climates have made agriculture compulsory in the long run. Agricultural societies are typically larger and richer than hunting and gathering communities. Thus, they are normally able to out-compete them for land and other resources.

\subsection{2}

\section{Geographic Regulation of Rates of Holocene Progress}

The advance of agriculture was highly variable, leading to societies highly dependent on agriculture in the southwestern Eurasia by about 9000 years ago and, in the same region, to the first states about 5000 years ago. In other areas - Western 
North America, Australia, and Argentina are the most extreme examples agriculture came late or not at all to areas highly suitable for agriculture. Each major region had a distinctive pattern of agricultural evolution and of evolution of associated technology and social organization. For example, the development of agriculture and state-level social organization in North and South America has many parallels to the trajectory in Western Asia, but the rate of development is rather slower. Diamond (1997) cogently argues that much of this variation is due to geographical factors. Evolution was fastest in Eurasia, the largest continent with the greatest scope for recombining innovations made by different peoples. Western Asia was especially well endowed with large-seeded grasses and animals preadapted to domestication. The New World was poor in both. Africa harbors more pathogens of humans and livestock than any other continent, and these act as brakes on the expansion of human populations.

\subsection{3}

\section{Collapses of Civilizations and Other Holocene Events}

Complex societies are not particularly stable systems. On the millennial time scale, collapses are quite common. In some instances, such the lowland Mayan city-states, the collapse was rapid, and depopulation was long-lasting and nearly complete. Climate change is one of the commonest explanations for such collapses, and everbetter data give archaeologists the chance to test such hypotheses more rigorously. For example, the Mayan collapse occurred during an extended drought (Curtis et al. 1996; Haug et al. 2003). The vagaries of climate affected the fortunes of less complexly organized societies as well; for example Arctic hunter-gatherers were particularly susceptible to changes in temperature (Jordan 1984; Dumond 1987). At lower latitudes drought is reckoned the cause of widespread cultural disruption among coastal and desert hunter-gatherers and agriculturalists in the western U.S. during what is termed the Medieval Climatic Anomaly (Lindsay 1986; Stine 1994; Jones et al. 1999; Kennett and Kennett 2000; Coltrain and Leavitt 2002) In as profound a way, but much earlier in time, the rapid onset of the extremely cold, dry Younger Dryas likely put an end to Natufian experiments with food production (Richerson et al. 2001).

Suffice it to say that the case for external controls on cultural evolution is quite strong. The record is not consistent with simple progress regulated entirely by internal constraints. Nonetheless, on the millennial time scale, even such a fastevolving system as culture is liable to meet some internal constraints to its evolution. Soltis et al. (1995) estimated the rates of change of sociopolitical evolution under cultural group selection, based on the rates of social extinction of clan-scale units observed by anthropologists in the Highlands of New Guinea. Very roughly, such rates of group selection support the sweep of a newly favored cultural practice in about 1000 years. Very roughly, the rate of progress of sociopolitical organization in human cultures in the Holocene has had a millennial time scale. Certainly, no trajectory of environmental change parallel to the growth of technical and sociopolitical complexity in the Holocene is currently known. 
Ruddiman (2003) presents evidence that the 'Anthropocene' geological era (the time during which humans have been a dominant geochemical/geophysical force) began, not in the last few hundred years, but about 8000 years ago with agriculture. According to his reading of the data, the current Holocene interglacial should have been a brief spike of warmth, as the Antarctic ice data suggest that the last several interglacials were, rather than an 11 600-year-long period of near-constant warmth. The earth is perhaps $0.8^{\circ} \mathrm{C}$ warmer than an entirely natural trajectory would predict. $\mathrm{CO}_{2}$ concentrations began to rise 8000 years ago as early farmers began to clear forests to make their fields. About 5000 years ago rice farmers began to create wetlands on a scale the led to increasing production of $\mathrm{CH}_{4}$. Ruddiman estimates that before the industrial era began, $\mathrm{CO}_{2}$ concentrations were $40 \mathrm{ppm}$ higher than natural levels and $\mathrm{CH}_{4}$ levels $250 \mathrm{ppb}$ higher. The rising concentrations of greenhouse gases due to agriculture were sufficient to counteract the expected cooling trend, leading to the 11600 -year-long span of the Holocene interglacial. This warming is sufficient at high latitudes $\left(2^{\circ} \mathrm{C}\right)$ to have prevented the spread of glaciers in the Canadian Arctic during the last millennium. These glaciers are the nucleus of the North American ice age ice sheet. Ruddiman also argues that the reforestation that accompanied the decline in agriculture in the wake of the Black Death and other plagues after $1300 \mathrm{CE}$ had a sufficient impact on greenhouse gas levels, sufficient to explain the Little Ice Age.

Currently, humans are on a path to produce the strongest climate perturbation in the last 65 million years (Barrett 2003 gives a striking graphical summary). The rapid warming of the earth (and/or the actions that we will have to take to prevent it) will necessarily produce a huge adaptive response, mostly cultural on the part of humans and mostly genetic and in the form of range adjustments on the part of other species. The form this evolution will take is difficult to predict, but the broad outlines of the challenge are straightforward. Climate scientists warn us that at least some of the changes in response to anthropogenic forcing will be large and abrupt (National Research Council 2002). The good news is that human culture arose, if our arguments here are correct, to cope with rapid unpredictable highamplitude climate variation. We are quite likely to adapt to the 'inevitable surprises' of anthropogenic climate change one way or another. The bad news is that in the past both complex and simple societies have often collapsed in the face of relatively minor climate challenges. Modern science and technology do give us unprecedented tools to understand climate change and devise responses. Modern social systems are also powerful systems for converting science and technology into effective widely supported public policy. Current attempts to reach a global consensus on managing climate change have been shaky at best, but the hour is still early. A reasonably safe assertion is that our immediate descendants are going to live in interesting times. 


\section{8}

\section{Conclusions}

Clearly, both internal and external processes have played roles in human evolution. We have here emphasized the possibility that ongoing climate deterioration has been the main driver of hominin evolution. The succession of adaptive grades of hominins with increasingly large brains and more sophisticated culture appear to have evolved as glacial climates have increasingly gripped the earth and as the amplitude of glacial-interglacial cycles has increased. That many mammalian lineages have experienced parallel brain size increases reduces the need to search for causes specific to the hominins. The hypothesis that the direct cause of large brains generally and human culture in particular is increasing high-frequency environmental variation currently lacks strong empirical confirmation; it is rather in the spirit of using theory to search for plausible proxies for past climates. We expect that much richer data on this aspect of climate change will be forthcoming over the next decade. Paleoanthropological data come more slowly, but increases in our sophistication are growing steadily. The hypothesis will be tested more stringently by these data. The cultural evolutionary events that have dominated the past few tens of thousands of years, perhaps the last few hundred thousand, also show dramatic responses to external events.

Internal processes must have shaped the details of biotic and cultural evolution in hominins. The fact that our lineage is the only one to have become so highly cultural, despite similar selection pressures from climate variation acting on most species, suggests that the genetic, developmental, and functional constraints operating in our lineage were weaker than in any other. Or, to put it positively, our lineage was uniquely preadapted to evolve complex culture in ways that are at least in part fairly obvious. The abrupt Pleistocene-Holocene transition and the relatively stable climates that characterize the Holocene constitute a natural experiment to probe the constraints limiting rates of cultural evolution (Richerson and Boyd 2001). Evidently, 11600 years has been too short a time for cultural evolution to reach an equilibrium adaptation to the Holocene environment. Granted, cultural evolution in the Holocene produced a massive adaptive radiation of cultures. But as impressively swift as it can be, internal constraints make cultural evolution a descentwith-modification process with plenty of similarities to, as well as differences from, organic evolution.

Whether hominin evolution can be considered progressive is a complex issue, given the many difficult issues raised by the concept of evolutionary progress (Nitecki 1988). Culture supports language, knowledge systems like science, social systems of great scale and sophistication, and technological adaptations of radically new sorts. The case for treating human culture as an evolutionary event on the scale of the evolution of multicellularity is strong. A skeptic might worry about the durability of human civilization. Suppose we define progress as evolution in a direction consistent with fulfilling humanistic goals by processes that are strong enough to override any external challenges and internal constraints our evolution is likely to face in the next few millennia. Our sense is that progressive evolution by this 
definition is possible. Science and technology have proven highly progressive in a different sense; they have greatly improved our understanding of the natural and social worlds and have thereby given us many practical tools for managing these worlds. Institutional reformers in the modern era have devised social systems that, however imperfectly, put the tools of science and technology to the service of meeting human wants and needs. For the first time in the history of the earth, a species has the tools with which it can aspire to control its own evolution. Whether these processes are powerful enough to overcome such constraints as the proliferation of sectarian ideologies, the concentration of political power in jealous nation-states armed with weapons of mass destruction, and the technical requirements of managing the global environment remains to be seen. Human evolution is currently an adventure in progress struggling to be an event. We have some individual and collective control over our fate, but not nearly enough control to make our future lives boring!

7.9

\section{References}

Aiflio, L. C., Wheeler, P. (1995) The expensive-tissue hypothesis: the brain and the digestive system in human and primate evolution. Current Anthropology 36, 199-221.

Alley, R. B. (2000) The Two-mile Time Machine: Ice Cores, Abrupt Climate Change, and Our Future. Princeton: Princeton University Press.

BarretT, P. (2003) Palaeoclimatology: Cooling a continent. Nature 421, 221-223.

Becquey, S., Gersonde, R. (2002) Past hydrographic and climatic changes in the Subantarctic Zone of the South Atlantic: the Pleistocene record from ODP Site 1090. Paleogeography, Paleoclimatology, Paleoecology 182, 221-239.

Boyd, R., Richerson, P. J. (1985) Culture and the Evolutionary Process. Chicago: University of Chicago Press.

Boyd, R., Richerson, P. J. (1996) Why culture is common but cultural evolution is rare. Proceedings of the British Academy 88, 73-93.

Bradley, R. S. (1999) Paleoclimatology: Reconstructing Climates of the Quaternary, Second Edition. San Diego: Academic Press.

Brofcker, W. S. (1995) The Glacial World According to Wally. Palisades, NY: Eldigio Press.

Bronowski, J. (1973) The Ascent of Man. Boston: Little, Brown.

Calvin, W. H. (2002) A Brain for All Seasons: Human Evolution and Abrupt Climate Change. Chicago: University of Chicago Press.

Coltrain, J. B., LeavitT, S. W. (2002) Climate and diet in Fremont prehistory: economic variability and abandonment of maize agriculture in the Great Salt Lake Basin. American Antiquity 67, 453-485.

Curtis, J. H., Hodell, D. A., Brenner, M. (1996) Climate variability on the Yucatan Peninsula (Mexico) during the past 3500 years, and implications for Maya cultural evolution. Quaternary Research 46, 37-47. 
Dean, C., Leakey, M. G., Reid, D., Schrenk, F., Schwartz, G. T., Stringer, C., Walker, A. (2001) Growth processes in teeth distinguish modern humans from Homo erectus and earlier hominins. Nature 414, 628-631.

deMenocal, P. B. (1995) Plio-Pleistocene African climate. Science 270, 53-59.

DEMenocal, P. B. (2004) African climate change and faunal evolution during the Pliocene-Pleistocene. Earth and Planetary Science Letters 220, 3-24.

Diamond, J. (1997) Guns, Germs, and Steel: The Fates of Human Societies: Norton: Jonathan Cape/Random House.

Ditlevsen, P. D., Svensmark, H., Johnsen, S. (1996) Contrasting atmospheric and climate dynamics of the last-glacial and Holocene periods. Nature 379, 810-812.

Dudiey, R. (2000) The evolutionary physiology of animal flight: paleobiological and present perspectives. Annual Review of Physiology 62, 135-155.

Dumond, D. E. (1987) The Eskimos and Aleuts. Revised Edition. London: Thames and Hudson.

Dunbar, R. I. M. (1998) The social brain hypothesis. Evolutionary Anthropology 6, 178-190.

Eldredge, N., Gould, S. J. (1972) Punctuated equilibria: an alternative to phyletic gradualism. In: Schopf, T. J. M. (Ed.), Models in Paleobiology. San Francisco: Freeman.

EPICA сомmunity members (2004) Eight glacial cycles from an Antarctic ice core. Nature 429, 623-628.

GaleF, B. G. JR. (1996) Social enhancement of food preferences in Norway rats: a brief review. In: Heyes, C. M., Galef, B. G. Jr. (Eds.), Social Learning in Animals: The Roots of Culture. San Diego: Academic Press.

Gould, S. J. (2002) The Structure of Evolutionary Theory. Cambridge, MA: Harvard University Press.

Graham, J. B., Dudley, R., Aguilar, N. M., Gans, C. (1995) Implications of the Late Paleozoic oxygen pulse for physiology and evolution. Nature 375, 117-120.

Haug, G. H., Gunther, D., Peterson, L. C., Sigman, D. M., Hughen, K. A., Amschlimann, B. (2003) Climate and the collapse of Maya civilization. Science 299, 1731-1735.

HENRICH, J. (forthcoming) Demography and cultural evolution: why adaptive cultural processes produced maladaptive losses in Tasmania. American Antiquity.

Henrich, J., Boyd, R. (1998) The evolution of conformist transmission and the emergence of between-group differences. Evolution and Human Behavior 19, 215-241.

Holland, H. D. (1984) The Chemical Evolution of the Atmosphere and Oceans. Princeton, NJ: Princeton University Press.

Jerison, H. J. (1973) Evolution of the Brain and Intelligence. New York: Academic Press.

Johnsen, S. J., Clausen, H. B., Dansgaard, W., Fuhrer, K., Gundestrup, N., Hammer, C. U., Iversen, P., Jouzel, J., Stauffer, B., Steffensen, J. P. (1992) Irregular glacial interstadials recorded in a new Greenland ice core. Nature 359, 311-313. 
Jones, T. L., Brown, G. M., RaAb, L. M., McVickar, J., Spaulding, W. G., Kennett, D. J., York, A., Walker, P. L. (1999) Environmental imperatives reconsidered. Current Anthropology 40, 137-170.

Jordan, R. H. (1984) Neo-Eskimo Prehistory of Greenland. In: Damas, D. (Ed.), Handbook of North American Indians: Arctic. Washington, DC: Smithsonian Institution.

Kennett, D. J., Kennett, J. P. (2000) Competitive and cooperative responses to climatic instability in coastal Southern California. American Antiquity 65, 379-395.

Klein, R. G. (1999) The Human Career: Human Biological and Cultural Origins, 2nd ed. Chicago: University of Chicago Press.

Lenski, G. E., Lenski, J. (1982) Human Societies: An Introduction to Macrosociology, 4th ed. New York: McGraw-Hill.

Lindsay, L. M. (1986) Fremont fragmentation. In: Condie, C. J., Fowler, D. D. (Eds.), Anthropology of the Desert West: Essays in Honor of Jesse D. Jennings. Salt Lake City: Anthropological Papers University of Utah.

Maryanski, A., Turner, J. H. (1992) The Social Cage: Human Nature and the Evolution of Society. Stanford: Stanford University Press.

Maynard Smith, J., Szathmary, E. (1995) The Major Transitions in Evolution. Oxford: Freeman/Spectrum.

McBrearty, S., Brooks, A. S. (2000) The revolution that wasn't: a new interpretation of the origin of modern human behavior. Journal of Human Evolution 39, 453-563.

McManus, J. F., Oppo, D. W., Cullen, J. L. (1999) A 0.5-million-year record of millennial-scale climate variability in the North Atlantic. Science 283, 971-974.

Moore, B. R. (1996) The evolution of imitative learning. In: Heyes, C. M., Galef, B. G. JR. (Eds.), Social Learning in Animals: The Roots of Culture. San Diego: Academic Press.

National Research Council (2002) Abrupt Climate Change: Inevitable Surprises. Washington, DC: National Academy Press.

Nitecki, M. H. (1988) Evolutionary Progress. Chicago: University of Chicago Press.

Opdyke, N. D. (1995) Mammalian migration and climate over the last seven million years. In: Vrba, E. S., Denton, G. H., Partridge, T. C., Burckle, L. H. (Eds.), Paleoclimate and Evolution, with Emphasis on Human Origins. New Haven, CT: Yale University Press.

Potтs, R. (1996a) Evolution and climate variability. Science 273, 922-923.

PoтTs, R. (1996b) Humanity's Descent: The Consequences of Ecological Instability. New York: Avon Books.

Poтts, R. (1998a) Environmental hypotheses of hominin evolution. Yearbook of Physical Anthropology 41, 93-136.

Pоттs, R. (1998b) Variability selection in hominid evolution. Evolutionary Anthropology 7, 81-96.

PRICE, P. W. (2003) Macroevolutionary Theory and Macroecological Patterns. Cambridge: Cambridge University Press. 
Ramirez Rozzi, F. V., Bermudez de Castro, J. M. (2004) Surprisingly rapid growth in Neanderthals. Nature 428, 936-939.

READER, S. M., LALAND, K. N. (2002) Social intelligence, innovation, and enhanced brain size in primates. Proceedings of the National Academy of Sciences USA 99, 4436-4441.

Rendell, L., Whitehead, H. (2001) Culture in whales and dolphins. Behavioral Q Brain Sciences 24, 309-382.

Richerson, P. J., Boyd, R. (2001) Institutional evolution in the Holocene: the rise of complex societies. In: Runciman, W. G. (Ed.), The Origin of Human Social Institutions. Oxford: Oxford University Press.

Richerson, P. J., Boyd, R. (2004) Not By Genes Alone: How Cultural Transformed Human Evolution. Chicago: University of Chicago Press.

Richerson, P. J., Boyd, R., Bettinger, R. L. (2001) Was agriculture impossible during the Pleistocene but mandatory during the Holocene? A climate change hypothesis. American Antiquity 66, 387-411.

Ruddiman, W. F. (2003) The anthropogenic greenhouse era began thousands of years ago. Climate Change 61, 261-293.

Scotese, C. R. (2003) Paleomap Project [website]. Available at http://www.scotese.com/.

Soltis, J., Boyd, R., Richerson, P. J. (1995) Can group-functional behaviors evolve by cultural group election? An empirical test. Current Anthropology 36, 473-494.

STEWART, J. (1997) Evolutionary progress. Journal of Social and Evolutionary Systems 20, 335-362.

STINE, S. (1994) Extreme and persistent drought in California and Patagonia during Medieval time. Nature 369, 546-549.

Tomasello, M. (1996) Do apes ape? In: Heyes, C. M., Galef, B. G. Jr. (Eds.), Social Learning in Animals: The Roots of Culture. New York: Academic Press.

Tooby, J., DeVore, I. (1987) The reconstruction of hominid behavioral evolution through strategic modeling. In: KinZey, W. (Ed.), Primate Models of Hominid Behavior. New York: SUNY Press.

Valentine, J. W. (1973) Evolutionary Paleoecology of the Marine Biosphere. Englewood Cliffs, NJ: Prentice-Hall.

Valentine, J. W. (1985) Biotic diversity and clade diversity. In: Valentine, J. W. (Ed.), Phanerozoic Diversity Patterns: Profiles in Macroevolution. Princeton, NJ: Princeton University Press.

Vekua, A., Lordipanidze, D., Rightmire, G. P., Agusti, J., Ferring, R., Maisuradze, G., Mouskhelishvili, A., Nioradze, M., Ponce de Leon, M., Tappen, M., Tvalchrelidze, M., Zollikofer, Ch. (2002) A new skull of early homo from Dmanisi, Georgia. Science 297, 85-89.

Verheyen, E., Salzburger, W., Snoeks, J., Meyer, A. (2003) Origin of the superflock of cichlid fishes from Lake Victoria, East Africa. Science 300, 325-329.

Vermeij, G. J. (1987) Evolution and Escalation: an Ecological History of Life. Princeton, NJ: Princeton University Press. 
Vrba, E., Denton, G. H., Partridge, T. C., Burckle, L. H. (1995) Paleoclimate and Evolution, with Emphasis on Human Origins: New Haven, CT: Yale University Press.

WAlker, T. D., Valentine, J. W. (1984) Equilibrium models of evolutionary species diversity and the number of empty niches. American Naturalist 124, 887-899.

White, T. D., Asfaw, B., DeGusta, D., Gilbert, H., Richards, G. D., Suwa, G., Howell, F. C. (2003) Pleistocene Homo sapiens from Middle Awash, Ethiopia. Nature 423, 743-747.

Whiten, A. (2000) Primate culture and social learning. Cognitive Science 24, 477-508.

Zachos, J., Pagani, M., Sloan, L., Thomas, E., Billups, K. (2001) Trends, rhythms, and aberrations in global climate $65 \mathrm{Ma}$ to present. Science 292, 686-693. 